\title{
LA DESIGUALDAD EN LAS ESTRUCTURAS COMPETITIVAS DEL FÚTBOL PROFESIONAL DE CÓRDOBA (ARGENTINA) EN LA DÉCADA DEL TREINTA*
}

\author{
Inequality in professional football's competitive structures in 1930s Córdoba \\ (Argentina)
}

Franco Reyna**

\begin{abstract}
Resumen
El artículo analiza determinadas prácticas y modalidades de institucionalización de la desigualdad en la profesionalización del fútbol en Córdoba (Argentina) en los años treinta, centrándose en los desequilibrios que se generaron entre los clubes en la configuración de las estructuras competitivas del juego. En ese marco, entidades con posiciones de poder y recursos acumulados previamente definieron y legitimaron simbólicamente modificaciones e innovaciones reglamentarias en los espacios de competencia con el fin de potenciar el desarrollo del espectáculo rentado. El acaparamiento y la distribución inequitativa de los bienes en juego en el mercado deportivo que resultaron de ese proceso afectaron el equilibrio competitivo entre las entidades e instituyeron nuevas formas de desigualdad en el contexto de un proceso de mayor mercantilización de la sociedad del espectáculo. Las fuentes documentales consultadas para realizar la investigación pertenecen a asociaciones deportivas, periódicos locales de la época y a entes gubernamentales de carácter municipal.
\end{abstract}

$<$ Fútbol $><$ Desigualdad $><$ Estructuras competitivas $><$ Profesionalización $>$

\begin{abstract}
This paper analyzes certain practices and forms of inequality institutionalization within the professionalization of football during the 1930s in Córdoba (Argentina), and it focuses on the imbalances between different clubs in the game configuration of the competitive structures. Within this framework, entities that held positions of power and that had previously accumulated resources defined, and symbolically legitimized, changes and regulatory innovations in the spaces of competition to enhance the development of the rented spectacle. As a result, the hoarding and inequitable distribution of the assets at stake in the sports market clearly affected the competition between the entities and instituted new forms of inequality, in the context of a process of greater commercialization of the entertainment society. The documentary sources used to carry out the research belong to sports associations, local newspapers, and municipal government entities.
\end{abstract}

$<$ Football $><$ Inequality $><$ Competitive structures $><$ Professionalization $>$

Recibido: 15/07/2018//Aceptado: 06/09/2018

* Este trabajo forma parte del proyecto colectivo "Grupos sociales, diferenciación y desigualdad social en una sociedad heterogénea y cambiante. Córdoba, 1870-1995”, Subsidio Trianual (2016-2019), Secretaría de Investigación, Universidad Católica de Córdoba.

** Instituto de Estudios Históricos-Centro de Estudios Históricos "Prof. Carlos S. A. Segreti", Profesor Asistente Exclusivo, Universidad Nacional de Córdoba (UNC), Argentina, franco2reyna@hotmail.com 
Reyna. La desigualdad en las estructuras competitivas del fútbol profesional de Córdoba (Argentina) en la década...

\section{Introducción}

Uno de los principales cambios socioculturales que se produjo desde comienzos de siglo fue el desarrollo de una nueva cultura de masas como resultado de la incorporación al mercado de diferentes formas de entretenimiento popular. Entre ellas se destacó el fútbol, que asistió a una progresiva transformación como espectáculo consumido por una población dotada de cada vez mayores recursos, capacidades y tiempo libre y caracterizado por una mayor especialización de sus actores, sistematización e institucionalización de sus estructuras, adecuación de sus infraestructuras y difusión y comercialización a través de los medios de comunicación. Estos nuevos productos culturales deportivos de masas se produjeron, circularon y consumieron a través de un mercado configurado a partir de relaciones cambiantes y dispares, que transformaron los momentos de ocio y la vida laboral de los sujetos.

Como un factor que atraviesa todos los procesos y estructuras sociales, la desigualdad ha afectado tanto las vinculaciones entre los grupos y los individuos, como el funcionamiento de las instituciones en el tiempo ${ }^{1}$. En el caso del fútbol, a pesar de que desde sus orígenes el deporte se fundaba en el principio de igualdad entre los participantes, en 1933 el proceso de transformación de su práctica como actividad rentada en la ciudad de Córdoba (Argentina) estuvo signado por diferentes instancias que ampliaron los desequilibrios y jerarquizaciones entre los diferentes actores del ámbito.

Este fenómeno de la profesionalización en el fútbol argentino ha sido tratado por autores como Alabarces (2000), Frydenberg (2005; 2015), Reyna (2015a; 2015b; 2017; 2018) y Roldán (2012), entre otros, quienes han estudiado la transición entre el amateurismo y el profesionalismo, las razones de su sanción, su impacto en la mercantilización y espectacularización del deporte y el modo en que lo experimentaron los sujetos. Sin embargo, su enfoque desde una perspectiva centrada en la desigualdad todavía es un territorio virgen, quizás debido a cierta tendencia a naturalizar desde lo deportivo las distancias sociales, económicas e institucionales existentes entre los distintos actores del campo. Han sido estudios internacionales de la sociología del deporte -entre ellos, Jarvie (2011) y Rohrer y Haller (2015)- los que han realizado incipientes aportes a esta problemática de la desigualdad desde una mirada contemporánea, interesada principalmente en las diferencias manifestadas tanto en el acceso de la población al deporte como en los movimientos de capitales entre instituciones, disciplinas y territorios. El análisis histórico desde una realidad concreta permite reconstruir en el tiempo las relaciones de poder que configuraron esos desequilibrios en diferentes espacios geográficos.

En ese marco, el objetivo de este artículo es analizar determinadas prácticas y modalidades de institucionalización de la desigualdad que se desarrollaron en la profesionalización de esta actividad en la década del treinta como parte de un proceso de mayor mercantilización de la sociedad del espectáculo. El énfasis está puesto en los desequilibrios que se generaron entre las entidades deportivas en la conformación de

1 La literatura sobre el tema es muy vasta, entre la que se destacan los aportes de clásicos como Dubet (2011), Kessler (2014), Reygadas (2008), Therborn (2015), Tilly (2015), entre muchos otros. 
las estructuras competitivas del juego, los cuales produjeron diversos mecanismos de acaparamiento de oportunidades, estratificación y exclusión.

Las desigualdades pueden referirse a las diferencias en los recursos que tienen los agentes para apropiarse de los bienes, a la inequidad en los procedimientos para la distribución de esos bienes o a la asimetría en la distribución final de los bienes (Reygadas, 2004 ; 24). Al respecto, desde una mirada institucional, este trabajo se centra tanto en los intercambios e interacciones como en las consecuencias que tuvieron lugar en el proceso de distribución de bienes materiales y simbólicos del espacio competitivo entre grupos con diferentes recursos y capacidades apropiados a lo largo de su trayectoria deportiva.

Para dar cuenta de este fenómeno, se examinan los actores que participaron del espacio competitivo deportivo, los formatos de torneos que regularon y sus innovaciones en el tiempo, las diversas condiciones de participación y relaciones de poder establecidas, las formas de representar las diferencias y las estrategias y resistencias de los afectados. Finalmente, se traza un balance de los resultados deportivos y económicos desencadenados como consecuencia de las transformaciones durante el profesionalismo y se indaga en la construcción y perdurabilidad de otras formas de desequilibrio en las estructuras competitivas del espectáculo.

En el intento de captar la profundidad de los procesos de reproducción de desigualdad y entender su persistencia, Juan Pérez Sáinz (2016: 13-14) rescata el tema del poder en el que estos se sustentan. El autor desplaza la mirada hacia la esfera de la distribución en los mercados básicos en los que los actores se desenvuelven y enfatizan sus asimetrías como condiciones que hacen posible la generación, circulación y la apropiación de excedentes. La selección de esas variables políticas y económicas que explican las desigualdades en el campo se comprende en función de la relevancia que estas tuvieron en el proceso de profesionalización del fútbol ${ }^{2}$. Respecto a ello, la aplicación de regulaciones concretas sobre el mercado deportivo afectó las condiciones de participación de los actores en el ámbito. La situación tomó estado público, promovió la mediación estatal y de la prensa y generó debates, resistencias y conflictos entre las partes bajo parámetros que incluso en la actualidad siguen siendo controvertidos. Sin embargo, estos factores políticos y económicos fueron influenciados también por dinámicas sociales, institucionales y deportivas propias del fútbol que complejizaron la producción de las desigualdades y sus efectos en el tiempo.

A propósito de esto, es posible afirmar que, sobre la base de relaciones de poder y capacidades acumuladas previamente, las interacciones entre los clubes en el contexto de la profesionalización del fútbol local estuvieron marcadas por la apropiación y distribución inequitativa e ilegítima que unos pocos hicieron de recursos, normas y clasificaciones en juego en el espectáculo deportivo. Esto perturbó el equilibrio competitivo entre las entidades y las formas de representar sus diferencias en la práctica, a la vez que delimitó un universo recreativo segmentado por grupos desiguales.

\footnotetext{
2 El análisis sigue la noción de "pluralismo controlado" de Ricoeur presente en la obra de Kessler (2014).
} 
Reyna. La desigualdad en las estructuras competitivas del fútbol profesional de Córdoba (Argentina) en la década...

Para realizar la investigación se consultaron fuentes documentales pertenecientes a las asociaciones deportivas encargadas de organizar y regular la práctica deportiva a nivel local -la Liga Cordobesa de Fútbol (en adelante LCF)- y nacional -la Asociación del Fútbol Argentino (en adelante AFA)-. A través de ellas es posible observar aspectos como la conformación estatutaria de las entidades, las formas de interacción entre sus miembros, la configuración de las competencias y las distintas normativas aplicadas sobre el espectáculo, las cuales instituyeron divisiones y asimetrías en su desarrollo. Para complementar esta información se recurrió a los principales periódicos locales de la época -Los Principios y La Voz del Interior-, a fines de identificar a los actores que participaron de ese universo deportivo y reconstruir sus experiencias, valoraciones y modalidades de intervención en el espacio público. Finalmente, se examinaron las actas y documentos del Honorable Concejo Deliberante de la Ciudad de Córdoba (en adelante, HCDC), ente gubernamental municipal de carácter legislativo, con el objetivo de reconstruir la actuación de los poderes públicos en el campo deportivo y las relaciones entabladas con las instituciones del ámbito.

\section{El marco competitivo del fútbol de Córdoba desde sus inicios}

Una vez que hacia finales del siglo XIX los trabajadores ingleses del ferrocarril introdujeron el fútbol en Córdoba, una de las dos ciudades más importantes del país detrás de Buenos Aires, se comenzaron a formar los primeros equipos para poder jugar contra otros similares. Difundida su práctica entre sectores de la elite local, la fundación de mayor cantidad de clubes a inicios del nuevo siglo motivó la necesidad de congregarse en torno a algún tipo de competencia regular que enfrentara a todos entre sí y consagrara a un ganador. Así, a fines de 1905, se creó por iniciativa de cinco clubes la primitiva Liga Cordobesa de Foot-ball para el desarrollo de los campeonatos oficiales bajo las leyes del "Football Association". Para afiliarse a ella, las entidades debían "estar bien constituidas" (poseer reglamentos y estatutos), disponer de campos de juego con dimensiones legales y amplias comodidades para los visitantes y pagar una suscripción anual de 20 pesos, además de que sus jugadores debían estar domiciliados en la ciudad y ser socios de su club (Liga Cordobesa de Football, 1910: 3-4). Solo un puñado de asociaciones locales, cuyos miembros eran de ascendencia inglesa o pertenecientes a la elite local, podía garantizar esas condiciones, a pesar de que la práctica se estaba difundiendo más allá del alcance de estos grupos.

En efecto, nuevos equipos iban apareciendo en diferentes rincones de la ciudad y, por no poder reunir los requisitos para adscribirse a la misma o por no tener interés en hacerlo, mantenían encuentros amistosos eventuales entre ellos. La informalidad de las estructuras que sostenían a la entidad federativa y el escaso conocimiento general que se tenía entonces del juego con frecuencia suscitaban interpretaciones variadas de las normas o su manipulación para imponer sus favoritismos. Su máximo órgano rector, el Consejo Directivo, fue rápidamente cooptado por intereses particulares (la mayoría de sus dirigentes provenía de un solo club), generando amplios contrastes y disparidades 
entre las instituciones contendientes. De este modo, el incremento de las disputas internas y las anomalías reglamentarias tornaron anacrónico y disfuncional su accionar.

De la mano de las nuevas asociaciones que fueron conquistando el espacio deportivo de la ciudad se instituyó en 1913 una nueva entidad encargada de organizar, controlar y fomentar la práctica del fútbol: la Federación Cordobesa de Football, que contaba con el aval de la Asociación Argentina de Football -reconocida por la FIFA para detentar la representación nacional- como entidad oficial del fútbol local. Los estatutos y reglamentos de la nueva entidad depositaban la autoridad en la Asamblea, el Consejo Superior (formado por miembros que no pertenecían a ninguno de los clubes) y el Consejo Divisional (compuesto por delegados de cada uno de ellos), procurando una división de poder más equitativa entre sus miembros y órganos de control independientes de ellos. La entidad estableció un calendario regular de competencia y fijó condiciones de participación que coadyuvaron a la transformación del fútbol que en sus marcos se practicaba en un espectáculo de masas.

La formación de marcos competitivos más formales que expandieran la oferta de productos culturales en el mercado deportivo más especializado implicaba mayores acuerdos y transacciones entre las instituciones. Entre otros aspectos, desde sus orígenes se sancionó una estructura competitiva dividida en categorías jerárquicas y se pautó una fórmula de movilidad entre las mismas a partir de mecanismos de ascensos y descensos que seguían como criterio los resultados deportivos, tal como sucedía en la gran mayoría de los torneos de liga en el país o en el exterior. El Consejo Superior de la entidad fijaba la categoría que correspondía a cada club de acuerdo a sus condiciones sociales, económicas y edilicias. A mayor posición, existían cupos limitados, mayores requisitos de acceso (como los referidos a las condiciones de sus instalaciones), mayor desembolso por inscripción y mayor representación en los órganos de decisión (Liga Cordobesa de Football, 1916: 4).

De esta manera, el sistema normativo de la LCF institucionalizó las diferencias económicas y sociales de partida de cada club. Si bien se aseguraba que en cada división sus afiliados tuvieran igualdad de oportunidades al momento de contender deportivamente, no generaba los marcos de equidad institucional para que todos disfrutaran de las mismas condiciones para obtener los incentivos y recompensas del juego. En términos de François Dubet (2011), dos grandes concepciones de la justicia social entraban en juego en ese escenario: la igualdad de posiciones y la igualdad de oportunidades. La primera refería a las brechas en los ingresos, las condiciones de vida y el acceso a los servicios y la seguridad entre las diferentes posiciones que ocupaban las entidades en la estructura competitiva. La segunda, por su parte, remitía a la posibilidad ofrecida a todas de ocupar las mejores posiciones en función de un principio meritocrático, el cual requería condiciones de equidad desde el punto de partida de las competencias.

En el marco de la LCF se inscribieron y compitieron, entonces, clubes con grandes disparidades en relación al nivel de especialización y disposición de tiempo libre de sus jugadores, la zona de anclaje territorial, la cantidad de socios, los medios económicos, la posesión de campos de juego y los apoyos institucionales con los que 
Reyna. La desigualdad en las estructuras competitivas del fútbol profesional de Córdoba (Argentina) en la década...

contaban. Amén de la calidad técnica de los jugadores, los diferentes bagajes de recursos y capitales que disponían las entidades influyeron en el desarrollo de sus estructuras asociativas y su competitividad deportiva.

De allí que las instituciones más poderosas $-\mathrm{y}$, por ende, con mayor capacidad de representación en la Liga- pudieran hacer uso de su posición de poder y modificar la distribución de recursos en las competiciones acorde a sus intereses. En efecto, los reglamentos de la Liga dejaban resquicios para que se utilizaran artilugios legales para decidir las promociones o permanencias de los equipos en las categorías estipuladas sin seguir los resultados los campeonatos. Así, por ejemplo, los clubes de primera división decidieron en 1926 aumentar de 7 a 9 los equipos de esa categoría para favorecer la permanencia en la categoría del club Universitario, uno de los más convocantes del medio, que había descendido ese año. Simultáneamente, se trató el ascenso a primera de Peñarol para completar el número de equipos, aunque este solicitó que no se avanzara en el proyecto. ${ }^{3} \mathrm{Si}$ bien no se aclararon los motivos, puede aventurarse que no disponían de recursos para poner en condiciones su campo de juego o que un mejor desempeño deportivo en segunda le generaba mayores ingresos recaudatorios.

Por otra parte, además de organizar los torneos periódicos de la ciudad, la LCF tenía la potestad para auspiciar encuentros amistosos y torneos oficiales de sus cuadros selectivos ${ }^{4}$ o de los clubes que la componían contra equipos de otras ligas nacionales o internacionales reconocidas por la FIFA. Este tipo de competiciones eran las más consumidas dentro del mercado deportivo de la época, convirtiéndose en una de las principales fuentes de ingreso y prestigio de las instituciones locales.

\section{Las modificaciones de las estructuras competitivas con el profesionalismo}

La sanción de la actividad rentada decretada por la LCF en 1933 implicó la incorporación como asalariados por medio de contratos de locación de servicios de un grupo de futbolistas dentro de los clubes pertenecientes a la categoría más importante y la denominada Intermedia ${ }^{5}$, mientras que las demás divisiones permanecieron siendo amateurs. Talleres, Belgrano, Instituto, Audax, Peñarol, Huracán, Palermo, 9 de Julio y Juniors eran las que en ese momento ocupaban los lugares privilegiados sobre la base de méritos deportivos previos. Esa posición les otorgaba el prestigio de pertenecer a la elite deportiva y les posibilitaba participar de algunos de los espectáculos más competitivos del escenario futbolístico local, además de permitirles controlar el mercado profesional y apropiarse de sus beneficios y disfrutar de mejores condiciones de representatividad en cargos directivos. Gracias a ello podían acceder, con claras disparidades internas, a mejores planteles de jugadores y mayor cantidad de aficionados, recursos e infraestructuras. Desde ese lugar, estas entidades instituyeron nuevas formas

3 Liga Cordobesa de Football. "Actas de Asamblea". 6 de abril de 1926, tomo 2, f. 30.

4 Como el Campeonato Nacional, que congregaba a equipos representativos de la mayor parte de las provincias argentinas.

5 Integrada por equipos de reserva de los mismos clubes de primera. 
de desigualdad en el espectáculo a través de la definición de nuevos marcos regulatorios de la competencia en el fútbol rentado.

Uno de los principales aspectos en los que estas instituciones intervinieron para mejorar sus condiciones de competitividad fue en la regulación del mercado de pases de jugadores, lo que generó grandes inequidades entre las instituciones. Aprovechando su control el Consejo Directivo de la LCF, en el que los nueve clubes profesionales tenían una representación mayoritaria (un voto cada uno contra dos entre la totalidad de las entidades de categorías amateurs, que representaban al 60\% del total de la liga), estas entidades fijaron reglamentaciones que impidieron el pase libre para sus jugadores con el fin de poder retenerlos pero sí lo otorgaron para las futbolistas de clubes amateurs, a los que pudieron adquirir libremente y sin grandes desembolsos. A su vez, también recurrieron a algunos mercados del interior todavía no profesionalizados para reforzar sus planteles, profundizando así los desequilibrios territoriales entre los grandes núcleos urbanos y las localidades más pequeñas de la región. Así, sobre la base de relaciones de poder asimétricas, los clubes profesionales construyeron un mercado de pases a su medida y concentraron en unos pocos el disfrute de los beneficios que la nueva condición rentada del fútbol suponía. Además, dentro de los mismos clubes profesionales se generaron desequilibrios, ya que algunos que poseían recursos acumulados en los años previos y/o gran capacidad de inversión proyectaron una estrategia de fuerte capitalización inicial para reforzar sus planteles. Solo esos pocos pudieron ofrecer espectáculos deportivos que expandieran el mercado de entretenimiento local, gracias a lo cual también crecieron sus estructuras deportivas ${ }^{6}$.

El otro gran instrumento empleado por las instituciones profesionales para optimizar su participación en el nuevo marco rentado fue la transformación de las estructuras competitivas bajo una lógica más mercantilista. Los clubes más convocantes de la ciudad utilizaron ese mecanismo para potenciar el desarrollo del espectáculo deportivo y acaparar los recursos que ponía en juego.

Una de las medidas más expeditivas fue la incorporación de nuevas competencias a las ya existentes. Al respecto, como los dos torneos oficiales disputados entre los nueve equipos de primera división profesional en 1933 terminaron con mucha antelación al fin de año (finales de octubre) se resolvió celebrar un nuevo torneo -Campeonato de Honor-. De esa manera, se aseguraban la posibilidad de extender la temporada deportiva y obtener nuevos recursos para sostener los compromisos económicos anuales asumidos con los jugadores rentados, ya que la mayoría de los clubes carecían de ellos.

Como los clubes seguían acusando dificultades económicas una vez finalizada la temporada inaugural, la herramienta que sus dirigentes utilizaron para dinamizar los campeonatos profesionales fue la alteración del cupo de participantes, a fines de mejorar la distribución de los recursos en juego. Esta cuestión entró en debate público después de que se tomara conocimiento de la decisión del Estado municipal de gravar con un impuesto del 10\% el producido bruto de las entradas de los partidos que involucraran a

\footnotetext{
${ }^{6}$ Para mayor información sobre este fenómeno y sobre las prácticas y experiencias de los sujetos en ese
} contexto, consultar: Reyna (2017). 
Reyna. La desigualdad en las estructuras competitivas del fútbol profesional de Córdoba (Argentina) en la década...

equipos profesionales de la ciudad a partir de la temporada oficial 1934 ${ }^{7}$. A decir de los dirigentes deportivos, los resultados financieros del profesionalismo no habían sido los esperados en el primer año, por lo que esa medida iba a restringir aún más los ingresos de los cuadros ${ }^{8}$. Si bien no se cuenta con estadísticas fiables sobre la performance económica de las entidades en ese lapso, era natural que ante las autoridades públicas presentaran un panorama pesimista para evitar las exacciones.

En ese panorama, las autoridades deportivas pusieron en discusión la elevada cantidad de equipos que jugaban en primera división. Existía consenso en que un medio como Córdoba no tenía el suficiente respaldo como para amparar los cuatro partidos que se debían jugar por reunión. De esta forma, antes de comenzar el segundo año del fútbol rentado, el Consejo Directivo de la LCF, avalado por una mayoría simple conformada por los votos de Talleres, Belgrano, Peñarol, Instituto, Juniors y Audax, resolvió el descenso a segunda división de los otros tres equipos pertenecientes a primera, que habían sido los últimos ascendidos: 9 de Julio, Palermo y Huracán ${ }^{9}$. Con la reducción de equipos pretendían brindar mejores espectáculos y contribuir a la viabilidad económica del certamen. Con ese propósito, instalaban la idea de que los intereses de unos pocos eran en beneficio del conjunto y sostenían la inevitabilidad de la desigualdad resultante.

La forma arbitraria que adquirió la implementación de esta decisión generó una gran polémica. Los seis clubes con mayor ingreso por entradas, previo acuerdo corporativo entre ellos, decidieron sobre el destino de las demás en función de lo que consideraban una falta de capacidad social y económica y de "espíritu de iniciativa" de las tres entidades ${ }^{10}$. En esa disposición mediaron más los méritos financieros que los deportivos. En efecto, como se puede comprobar en la Tabla 1, estos tres equipos fueron los que menores recaudaciones percibieron durante las competencias oficiales de 1933, pero no necesariamente todos ocuparon las últimas posiciones: 9 de Julio había aventajado en las posiciones finales a Audax e Instituto, aunque Palermo y Huracán sí terminaron en los últimos dos lugares. Así, los clubes más convocantes buscaban que los beneficios fueran proporcionales a la producción de cada uno: los que más ingresos generaran serían respaldados con la posibilidad de participar en un torneo más exclusivo. Fue esta la primera vez en la historia de la LCF en que la entidad excluía a algunos de sus clubes del derecho de pertenecer a la categoría deportivamente ganada.

7 Archivo Histórico de la Municipalidad de Córdoba (AHMC). Actas de Sesiones del Concejo Deliberante. Liga Cordobesa de Football. 23 de octubre de 1933, f. 357; AHMC. Documentos del Concejo Deliberante. Liga Cordobesa de Football. 30 de octubre de 1933, ff. 310-312.

8 AHMC. Documentos del Concejo Deliberante. Liga Cordobesa de Football. 22 de diciembre de 1934, ff. 487-489.

9 Liga Cordobesa de Football. "Actas de Asamblea. 14 de febrero de 1934, tomo 2, ff. 115-118.

10 "La prepotencia del número y de la fuerza eliminó a los pequeños clubs". (18 de febrero de 1934). Los Principios, p.11. 
Tabla 1. Recaudaciones de los clubes de primera división durante los torneos del primer año profesional

\begin{tabular}{ccccc}
\hline Clubes/Torneo & $\begin{array}{c}\text { Preparación } \\
(\mathbf{1} \text { rueda) }\end{array}$ & $\begin{array}{c}\text { Oficial } \\
\text { (2 ruedas) }\end{array}$ & $\begin{array}{c}\text { Honor } \\
\text { (Final) }\end{array}$ & Total \\
\hline 9 de Julio & $\$ 889,33$ & $\$ 1.508,49$ & $\$ 436,59$ & $\$ 2.834,41$ \\
\hline Audax & $\$ 1.562,54$ & $\$ 2.805,46$ & $\$ 693,38$ & $\$ 5.061,38$ \\
\hline Belgrano & $\$ 6.733,94$ & $\$ 11.763,81$ & $\$ 2.238,92$ & $\$ 20.736,67$ \\
\hline Huracán & $\$ 1.412,50$ & $\$ 1.399,99$ & $\$ 259,28$ & $\$ 3.071,77$ \\
\hline Instituto & $\$ 3.434,17$ & $\$ 3.651,86$ & $\$ 989,01$ & $\$ 8.075,04$ \\
\hline Juniors & $\$ 892,08$ & $\$ 7.501,44$ & $\$ 824,15$ & $\$ 9.217,67$ \\
\hline Palermo & $\$ 706,32$ & $\$ 2.402,46$ & $\$ 337,01$ & $\$ 3.445,79$ \\
\hline Peñarol & $\$ 4.587,34$ & $\$ 6.095,94$ & $\$ 368,28$ & $\$ 11.051,56$ \\
\hline Talleres & $\$ 6.941,79$ & $\$ 7.222,37$ & $\$ 2.036,24$ & $\$ 16.200,40$ \\
\hline Total & $\$ 27.160,01$ & $\$ 44.351,82$ & $\$ 8.182,86$ & $\$ 79.694,69$ \\
\hline
\end{tabular}

Fuente: Elaboración propia sobre la base de datos suministrados por "La mayor recaudación de la temporada la ha logrado el C. Belgrano". (14 de diciembre de 1933). La Voz del Interior, p. 13.

No era un dato menor que, con los descensos de los equipos, los damnificados verían reducir drásticamente los ingresos por recaudaciones, los cuales les permitían subsistir y cumplir con los compromisos asumidos. Asimismo, corrían el riesgo de que les fueran acaparados sus mejores valores dada la reglamentación de pases vigente al momento. Finalmente, la situación también afectaba la posibilidad que tenían sus jugadores de seguir cobrando estipendios como profesionales, ya que debían volver a actuar en las filas del amateurismo. El descontento generalizado de los futbolistas no tuvo suficiente eco en la prensa, más pendiente de la situación institucional de los clubes.

Por otro lado, en relación con los torneos amateurs, el Consejo Directivo estableció que a finales de la temporada que empezaba no habría descensos en la primera división y que el campeón de segunda ascendería a primera siempre y cuando poseyera personería jurídica y cancha en estado reglamentario. Así, el grupo selecto se cerraba en sí mismo y ponía trabas a la admisión de clubes de segunda división a la categoría superior, pero no a la incorporación de sus mejores jugadores, ensanchando aún más la brecha institucional y deportiva entre unos y otros.

Con ambas disposiciones, se dejaba librada la regulación de las competencias a aquellas entidades que disponían de los recursos e influencias necesarias para controlar corporativamente los resortes de poder y dictar las reglas de juego. Se desconocieron la trayectoria de las instituciones damnificadas y los derechos igualitarios reconocidos para todos los clubes en los mismos estatutos de la Liga. El modelo de oportunidades se imponía a medida que las posiciones se volvían más escasas: el debate no se centraba tanto en la reducción del número de equipos como en la manera de ocupar los espacios y en la equidad del árbitro (Dubet, 2011: 57-58). 
Reyna. La desigualdad en las estructuras competitivas del fútbol profesional de Córdoba (Argentina) en la década...

Las inequidades originadas en este proceso fueron también respaldadas por dispositivos simbólicos que reconocían estas diferencias como aceptables. Siguiendo el análisis de Tilly (2000), en la interacción con los otros actores institucionales del ambiente y amparados en su grado de contribución tanto deportiva como financiera al espectáculo, los clubes más poderosos construyeron categorías simbólicas para apuntalar posiciones (clubes grandes/clubes chicos; clubes profesionales/clubes amateurs), las cuales establecían relaciones jerárquicas entre ellos y justificaban la producción y distribución asimétrica de recursos. A partir de estas formas de identificación, legitimaron el uso de dispositivos legales para excluir a los que tenían un estatus inferior en el mercado y acaparar entre menos contendientes los beneficios del nuevo modelo deportivo. Así, sobre la base de mecanismos de diferenciación de este tipo montaron un nuevo orden competitivo.

Estas modalidades no fueron exclusivas del fútbol cordobés. Ya desde el momento en que se profesionalizó la práctica en Buenos Aires en 1931, 18 de las entidades más poderosas se desafiliaron de la Asociación Amateurs Argentina de Football (que no daba el aval para su sanción) y constituyeron su propia federación, la Liga Argentina de Football. Muchos de los clubes allí denominados "chicos" fueron excluidos de la nueva estructura orgánica sin que primara un criterio de selección deportivo y se agruparon en torno a la Asociación Argentina de Football. Las desigualdades se profundizaron con la unión de ambas federaciones en 1934 en la flamante Asociación del Fútbol Argentino: automáticamente todos los equipos de la liga profesional pasaron a formar parte de la primera división y los de la amateur, de la segunda; al igual de lo que sucedió en Córdoba, a las dos entidades que menos recaudaron en la liga profesional se les impidió jugar en primera. Paralelamente, los estatutos de la flamante organización definieron que cada uno de los clubes que actuaba en primera contara con un delegado en el Consejo Directivo, mientras que todos los de segunda tendrían solo uno, afectando sus condiciones de representatividad ${ }^{11}$. Al año siguiente, un informe de AFA advertía, entre varias razones, que la concentración que se estaba dando de las mejores figuras en pocos clubes llevaba a un desequilibrio en la capacidad socioeconómica y deportiva de los equipos. ${ }^{12}$ A partir de ello, los dirigentes porteños realizaron diferentes ensayos en el campeonato profesional para lograr una mejora en sus finanzas, las que también incluyeron la reducción de equipos.

En otros países, como España, se ensayaron otros medios para optimizar los beneficios de la naciente competencia profesional sancionada en $1926^{13}$. Al respecto, como solución al aumento de las erogaciones que implicaba el sostenimiento de los contratos a los jugadores resolvieron expandir territorialmente su mercado de espectáculos deportivos. En efecto, dos años después crearon un nuevo marco competitivo de índole nacional como complemento al modelo deportivo vigente de carácter regional. Sin embargo, en Argentina no estuvieron dadas las condiciones para ello y los torneos

\footnotetext{
${ }^{11}$ Asociación del Football Argentino. "Memoria y Balance General”. 1934, p. 13; Asociación del Football Argentino. "Estatuto y Reglamento General". 1940, p. 17.

${ }^{12}$ Asociación del Football Argentino. "Memoria y Balance General". 1935, pp. 81-95.

${ }^{13}$ La temática ha sido trabajada, entre otros, por autores como Bahamonde (2011), Otero Carvajal (2003), Pujadas y Santacana (2001) y Sanjurjo (2011).
} 
siguieron teniendo un alcance citadino como consecuencia de las grandes distancias y las difíciles condiciones geográficas, comunicacionales y económicas del país. De allí que cada federación oficial definió de manera autónoma sus propios mecanismos para ejecutar el profesionalismo.

Las modalidades impulsadas en Córdoba suscitaron reacciones de los distintos frentes afectados para contrarrestar las inequidades. Los canales de protesta de las entidades estuvieron signados por las diferencias de rango entre ellas. Por un lado, las autoridades de las instituciones descendidas de la primera división, que contaban con personería jurídica, recurrían ante terceros por vías legales para protestar por la violación de los pactos deportivos y legales por parte de los integrantes del Consejo Directivo. Además de levantar actas ante escribano público, gestionaron la intermediación del gobierno provincial a través de la apertura de un expediente en la Inspección de Sociedades Anónimas, aunque su reclamo no fue atendido ${ }^{14}$. En estas intervenciones, el Estado aparecía representado como el único actor externo que podía reparar injusticias y restituir derechos pero no socavar las desigualdades, que eran atribuidas por la propia dinámica deportiva.

Por otro lado, los clubes de segunda división se valieron de medios más informales a su alcance y apelaron a los recursos que les ofrecía la misma entidad federativa a la que pertenecían. El eje estaba puesto en la necesidad de modificar la desigual distribución de poder entre las instituciones a fin de poder ampararse reglamentariamente ante injusticias y atropellos de los más poderosos. Al respecto, sus dirigentes presentaron un petitorio solicitando la representación proporcional ante los cuerpos colegiados: tres representantes de segunda y uno de tercera en el Consejo Directivo de la Liga y un delegado por cada club de división inferior en la Asamblea General; además, pretendían la equiparación de derechos entre los clubes de divisiones inferiores y los de primera en lo que concernía a los pases de jugadores y el restablecimiento de los ascensos y descensos en primera, segunda y tercera división ${ }^{15}$. De ese modo, buscaban reducir las distancias con las posiciones superiores a fin de mejorar sus oportunidades. Sin embargo, como sucedió veces anteriores, ambas demandas fueron rechazadas.

Tampoco fue efectiva a los intereses de los clubes "chicos" la asamblea que estos solicitaron a la Liga para que se reconsiderara la resolución del Consejo Directivo. La reunión se celebró en marzo de 1934 y contó con la fiscalización de un representante de la Inspección de Sociedades Anónimas, quien avaló la votación que confirmaba la reducción de equipos en primera ${ }^{16}$. Las instancias democráticas también sirvieron para legitimar la desigualdad. Como los clubes afectados carecían de representación suficiente en la dirección de la LCF, sus canales institucionales para revertir los acontecimientos estaban bloqueados.

\footnotetext{
14 “Contemplan la situación de la entidad socios del Club atlético 9 de Julio". (3 de marzo de 1934). La Voz del Interior, p. 13.

15 "Hoy se elevará el petitorio de los clubs de 2a". (31 de enero de 1934). Los Principios, p. 9.

16 "La asamblea de la Liga confirmó anoche el descenso de los chicos". (21 de marzo de 1935). Los Principios, p. 13.
} 
Reyna. La desigualdad en las estructuras competitivas del fútbol profesional de Córdoba (Argentina) en la década...

La calle y la prensa fueron otros espacios públicos de movilización utilizados por jugadores y simpatizantes de estas entidades. Por caso, en el día de la asamblea una barra numerosa de estos se había congregado en las afueras del local de la Liga y prorrumpió con gritos y silbidos a la decisión del cuerpo ${ }^{17}$. Eran sectores que habían aunado posiciones en torno al asunto e intentaban conformarse como un frente de resistencia para respaldar la actuación de sus delegados y reparar la injusticia sufrida.

Por su parte, los órganos de difusión periodísticos encabezaron la defensa de las entidades descendidas y reaccionaron uniformemente ante las formas arbitrarias que había adquirido la situación. A la par que publicaban opiniones de los aficionados que seguían la misma línea editorial sobre esta problemática, en sus páginas discutían el carácter de clubes "grandes" que se atribuían los mentores de la iniciativa, subrayando que algunos de esos equipos no habían superado en las posiciones a quienes anteriormente les habían "arrebatado" sus jugadores para reforzar sus planteles y ahora determinaban su descenso. En cuanto al orden económico, ponían como ejemplo que Belgrano y Talleres habían construido sus estadios con dineros municipales y que aún no habían pagado; que Juniors iba a levantar el suyo en terreno y con dineros fiscales y que los otros tres ni siquiera eran propietarios de sus terrenos. Agregaban, además, que sobre todos ellos pesaban acusaciones de sobornos de jugadores ${ }^{18}$. De esta manera, desde la prensa se ponían en tela de juicio las posiciones atribuidas por los más encumbrados en la medida en que su accionar generaba discriminaciones que obstaculizaban la igualdad de oportunidades desde la que todos los clubes debían partir para mejorar su posición sobre la base del mérito.

Las entidades deportivas también idearon estrategias alternativas para revertir la situación generada, como la fusión (deportiva, más no institucional) con otros clubes en los términos legales que les permitiera afiliarse unitariamente a la Liga para intervenir en los torneos. Por ejemplo, 9 de Julio pretendía permanecer en primera asociándose con otro vecino del barrio Alberdi, Universitario: si se acusaba a la primera por falta de capacidad social y económica, el club estudiantil la aportaría gracias a la gran cantidad de socios y simpatizantes que tenía, lo que era una garantía de "éxito mercantil" para la propuesta. Y con la situación deportiva no se podían poner reparos dado que terminó el torneo en el cuarto puesto y ahora se sumarían nuevos elementos a sus filas. En definitiva, estas maniobras eran también un intento de compensar las disparidades entre las instituciones y equilibrar las desigualdades existentes.

Sin embargo, el Consejo Directivo de la LCF hizo caso omiso a cada una de las propuestas formuladas y reglamentó la forma de disputa de la temporada 1934 solo entre los seis equipos que quedaban en primera. No habría descensos en primera, pero sí un ascenso para los de segunda.

\footnotetext{
17 "La asamblea de la Liga confirmó anoche el descenso de los chicos". (21 de marzo de 1935). Los

Principios, p. 13.

18 "La grandeza de los despojadores". (20 de febrero de 1934). Los Principios, p. 9.
} 


\section{Secuelas y reconfiguraciones del marco competitivo}

Cumplida la primera temporada de vigencia del impuesto municipal y de la reducción de equipos en primera, en los informes periodísticos se dejaba entrever que los resultados deportivos y financieros del sector profesional habían estado por debajo de las expectativas originalmente creadas. A la par que entendía que no había mejorado la calidad de los espectáculos brindados, la prensa señalaba que la mayoría de las instituciones había agravado su situación económica dados los costos que implicaba el mantenimiento de los planteles profesionales y las exacciones que soportaban por el gravamen municipal que había comenzado a cobrarse a los partidos profesionales. Ello se daba a pesar de que la situación económica había sido menos crítica que el año anterior y que los precios de las entradas habían sido rebajados para fomentar la asistencia a los estadios ${ }^{19}$.

En efecto, las recaudaciones de los seis clubes profesionales en los matches del certamen preliminar de 1934 habían disminuido con respecto a los mismos encuentros del año anterior en más de \$3.000, a lo que debía sumarse la merma generada por el gravamen municipal. Al finalizar la temporada, solo tuvieron un saldo económico favorable quienes habían mejorado su campaña deportiva comparado al año anterior: Audax y Talleres ${ }^{20}$. La información que los periódicos publicaban era recabada de los clubes y la LCF, por lo que podría haber estado manipulada en función de los intereses de estas entidades, que estaban en plena disputa con el municipio por la cuestión impositiva. Como los cronistas empatizaban con la realidad de las entidades profesionales, especulaban que esta situación podía perjudicar seriamente a casi 200 familias que se mantenían con los sueldos y primas del fútbol y que podrían verse reducidos o eliminados ${ }^{21}$. Para ilustrar esta cuestión, habría que tener en cuenta que en un encuentro donde se recaudaban $\$ 200$, si se descontaban los porcentajes que se llevaban la Liga y el impuesto municipal, cada club se quedaba con $\$ 80$, con los cuales debía afrontar los gastos pertinentes a la organización del cotejo más los viáticos y primas de un plantel de al menos once o quince jugadores, que no bajaban de los $\$ 15 \mathrm{o}$ \$20 por persona: las pérdidas eran notoriamente visibles, aun cuando disponían de los ingresos gravados 22 .

Finalmente, en 1935 el Concejo Deliberante aceptó derogar el impuesto al fútbol profesional una vez que terminara la temporada, en virtud de que la experiencia había significado un mayor empobrecimiento de las instituciones deportivas de la ciudad ${ }^{23}$. El porcentaje confiscado quitaba a las entidades la oportunidad de permanecer solventes,

19 “Eliminados los chicos se cumplieron los propósitos de los grandes?”. (9 de mayo de 1934). Los Principios, p. 9.

${ }^{20}$ Este último, que se coronó campeón en el campeonato oficial, superó en más de 8 mil pesos lo percibido en 1933, pero con los descuentos reglamentarios el aumento fue solo de \$2.600. "Sus ingresos consiguió aumentar en el año 1934 el Club Atlético Talleres". (31 de enero de 1935). La Voz del Interior, p. 10.

21 "Debe derogarse el impuesto que grava al fútbol". (22 de junio de 1934). La Voz del Interior, p. 14.

22 "No abonaron el impuesto los clubs Instituto y Juniors". (4 de mayo de 1934). Los Principios, p. 10.

${ }^{23}$ AHMC. Actas de Sesiones del Concejo Deliberante. Liga Cordobesa de Football. 1935, tomo 1, ff. 8-16, 259-268, 300. 
Reyna. La desigualdad en las estructuras competitivas del fútbol profesional de Córdoba (Argentina) en la década...

mantener o realizar mejoras en sus instalaciones y comprometía los servicios que prestaban a la comunidad ${ }^{24}$. Todo esto profundizaba las distancias entre las instituciones y afectaba sus condiciones de participación en los campeonatos. De allí que varios cuadros de divisiones inferiores de los clubes con fútbol profesional (14) abandonaran los torneos en pleno transcurso de la temporada y que, al comenzar la siguiente, Audax, Belgrano, Instituto y Peñarol suprimieran la cantidad de escuadras inscriptas en la LCF ${ }^{25}$. La reorganización de sus estructuras deportivas tendiente a aminorar la inscripción de equipos que muchas veces terminaban desertando fue una de las estrategias pergeñadas por las instituciones para lograr un control más eficaz de sus recursos. Así, los cuadros de la sección amateur de los clubes profesionales terminaban siendo los sacrificados para la prosperidad del espectáculo.

Algo similar sucedía con las instituciones amateurs de la LCF, cuyos equipos de divisiones menores también comenzaron a mostrar indiferencia en su participación en los certámenes. Ese año, de los 112 equipos pertenecientes a las divisiones inferiores que se inscribieron, 35 se retiraron antes de finalizar los torneos ${ }^{26}$. Esta dinámica perduró en los años siguientes. Varios de los certámenes oficiales de esas categorías terminaban siendo disputados por una cantidad mucho menor de equipos que los que habían empezado. Por caso, tanto en el campeonato de Tercera C de 1936 y de Tercera B en 1937, empezaron ocho clubes y terminaron solo tres ${ }^{27}$.

La merma de equipos de las divisiones inferiores en la LCF podría explicarse por los mayores costos y requisitos formales que implicaba jugar en la entidad oficial y por la exigencia de mayor especialización física y técnica que suponía; también por la mayor pujanza que comenzaron a tener en la época otros circuitos deportivos amateurs alternativos que organizaban torneos entre equipos del fútbol aficionado independientes a la LCF ya desde la década anterior. Eran agrupaciones de equipos dependientes de la administración pública, centros estudiantiles y profesionales, casas comerciales e industriales, círculos militares y áreas vecinales de la ciudad, entre otros, que ampliaban el espectro de la oferta recreativa en torno al fútbol. En general, se movían en circuitos geográficos diferentes a los de la LCF o no se encontraban financiera ni estructuralmente aptas para amoldarse a las exigencias que ella requería: inscripción, cuotas, terrenos de juego y, en algunos casos, personería jurídica, etc. Sus torneos tenían en el anclaje territorial su elemento cohesionador, en una época en que el barrio tomaba fuerza como elemento organizador de la vida social y el fútbol contribuía a delinear nuevas identidades en el entramado urbano ${ }^{28}$. Los bienes y servicios culturales que estas entidades generaban no participaron del proceso de espectacularización de la práctica

\footnotetext{
${ }^{24}$ En 1934, Belgrano tuvo que tributar al municipio poco menos de 3 mil pesos, mientras que Talleres contribuyó con alrededor de $\$ 2.500$. El aporte del resto de los clubes profesionales era insignificante para las arcas del Estado, pero vitales para su propia subsistencia. Liga Cordobesa de Football. "Actas de Asamblea". 15 de febrero de 1935, tomo 2, ff. 128-129.

${ }^{25}$ Liga Cordobesa de Football "Campeonatos". 1934-1935.

${ }^{26}$ Liga Cordobesa de Football. "Campeonatos". 1934, f. 2.

${ }^{27}$ Liga Cordobesa de Football. “Campeonatos”. 1936, f. 17; 1937, f. 10.

${ }^{28}$ Para un análisis más pormenorizado sobre la construcción de identidades barriales a partir de la relación entablada entre los clubes y el territorio, consultar: Frydenberg (2011) y Reyna (2015a).
} 
deportiva en el que estaban inmersos los clubes de la Liga, pero sí contribuyeron a estos en la formación de una masa de jugadores y espectadores que consumían sus productos.

En relación con los clubes que disputaban los torneos profesionales de la LCF, en esos años la afiliación se mantuvo sin variaciones a pesar de las vicisitudes acaecidas en el fútbol local, mientras que la de la sección amateurs sufrió pequeñas modificaciones como la incorporación de dos instituciones provenientes de una ciudad aledaña a Córdoba, Alta Gracia $^{29}$. La admisión de cuadros de reconocida trayectoria de otras localidades de la provincia fue otro mecanismo para estimular la competitividad de los torneos y favorecer un incremento en las recaudaciones, a la vez que significó un perjuicio para el fútbol de esa región, que profundizaba sus diferencias con el capitalino ${ }^{30}$.

De esta manera, casi la totalidad de las instituciones mostraron la voluntad de seguir formando parte de la entidad madre, pese a que los balances económicos de la mayoría de ellos hubiera dado negativo, a que hubiera habido muchas resistencias a las arbitrarias decisiones tomadas por la Liga o a que muchos se hubieran visto afectados por la pérdida de sus principales jugadores contratados por equipos profesionales locales o nacionales ${ }^{31}$. Amén del prestigio que dicha pertenencia suponía y de la posibilidad que otorgaba de seguir participando en los más altos niveles de competitividad deportiva que ofrecía la ciudad, prescindir de la afiliación a la Liga podía acarrear la ruina de una institución, ya que en la mayoría de los casos el fútbol era su principal factor de sostén y atracción de socios y su deserción hubiera significado un gran perjuicio para el desarrollo de las tareas sociales, deportivas y culturales que estas cumplían en los diferentes barrios de la ciudad ${ }^{32}$.

En los años sucesivos, la organización del fútbol profesional de la LCF siguió evidenciando situaciones irregulares en orden a conservar privilegios y asegurar recursos para los equipos profesionales. Por un lado, los que estaban con posibilidades de bajar de categoría iniciaban gestiones para que se derogaran los descensos; incluso, a veces en la prensa se rumoreaba que, para definir la posición de un club ante este asunto, algunos pedían dinero o jugadores a los promotores de la iniciativa ${ }^{33}$. En otras ocasiones, los clubes profesionales pretendían incorporar a la máxima divisional a entidades de gran convocatoria del certamen amateur para incrementar las recaudaciones. Al respecto, en 1939 se empezó una campaña para solicitar el ascenso por decreto del club Universitario en función de su gran trayectoria en el medio, su arraigo en la afición y su poderío económico y deportivo ${ }^{34}$. La incorporación a primera del club estudiantil fue aprobada por el Consejo Directivo con el voto favorable de los ocho clubes de primera y el rechazo de los dos delegados de las categorías amateurs ${ }^{35}$. La resolución despertó el

\footnotetext{
${ }^{29}$ Liga Cordobesa de Football. "Campeonatos”. 1934-1939.

${ }^{30}$ En 1941 también se incorporó el equipo más poderoso de la ciudad de San Francisco, Sportivo Belgrano.

${ }^{31}$ Para mayores referencias, consultar: Reyna (2017).

32 Para mayores referencias, consultar: Reyna (2018).

33 "Entretelones de un pedido". (5 de octubre de 1936). Los Principios, p. 10.

34 "No debe primar sentimentalismo cuando se trata de reformar un artículo del estatuto de la Liga". (3 de febrero de 1939). Los Principios, p. 13.

35 “Ascendió Universitario". (1 de marzo de 1939). Los Principios, p. 11.
} 
Reyna. La desigualdad en las estructuras competitivas del fútbol profesional de Córdoba (Argentina) en la década...

entusiasmo de muchos allegados al club: a los días siguientes, se presentaron cerca de 500 solicitudes de $\operatorname{socios}^{36}$. De esta manera, las fronteras entre quienes pertenecían y quienes no al círculo privilegiado se volvían permeables y solo se modificaban arbitrariamente cuando la incorporación de nuevos actores podía mejorar los canales de acceso a los recursos.

Con esos cambios en las competencias y alentados por la situación económica más auspiciosa del país, al año siguiente las recaudaciones de las entidades repuntaron en más de $\$ 8.000$ globales respecto a las del Torneo Preparación del año anterior ${ }^{37}$. Sin embargo, ese incremento benefició nuevamente a las instituciones profesionales y no a la totalidad de los clubes afiliados, según demuestran los balances de las utilidades percibidas por la LCF en esos años: el crecimiento gradual que esta comenzó a tener desde 1938 no varió demasiado el año de la incorporación de Universitario, quien arrastró sus recaudaciones a la categoría superior ${ }^{38}$. Esto implicó un nuevo perjuicio a las arcas de las instituciones amateurs, que perdieron los ingresos que percibían gracias a las convocatorias de dicho club, ahondando las desigualdades en el mercado de consumo deportivo.

\section{Desigualdades previas y asimetrías competitivas}

En términos generales, las diferentes variaciones en las estructuras de competencia deportiva durante la primera década de profesionalismo se pueden explicar, en parte, por la disputa que los clubes tuvieron por alcanzar la hegemonía deportiva y por apropiarse y regular los recursos en juego en la práctica deportiva. En esa puja intervinieron actores con disímiles relaciones de poder y procesos históricos de acumulación de inequidades. El éxito deportivo era uno de los principales factores de atracción de adherentes y recursos en la práctica y su disposición era fundamental para sanear y asegurar el funcionamiento de las entidades, realizar mejoras en sus instalaciones, promover nuevas actividades socioculturales y deportivas o invertir en la contratación de nuevas estrellas para el reforzamiento del plantel de futbolistas. A partir de ello, los clubes atraían el interés de nuevos sectores a su vida asociativa, abrían nuevos mercados de consumo y generaban nuevas formas de ingresos. Talentos deportivos, asociados, aficionados, rentas y prestigio eran algunos de los principales capitales por los que clubes con capacidad diferencial pugnaban obtener y usufructuar, pero la inequidad en los procedimientos para su distribución suscitó tensiones y conflictos entre ellos e influyó en el desarrollo de las competencias.

Una vez que las modificaciones en los reglamentos de competencia deportiva de la LCF excluyeron a algunas entidades del círculo máximo, las oportunidades entre las demás competidoras de ese nivel teóricamente quedaron equilibradas, pero ello no

\footnotetext{
36 "Cerca de 500 solicitudes de socios se presentaron en Universitario". (8 de marzo de 1939). Los Principios, p. 9.

37 "En la preparación de este año se recaudaron 8174.30 más que en 1938". (21 de junio de 1939). Los Principios, p. 11.

${ }^{38}$ Liga Cordobesa de Football. "Actas de Asamblea". 10 de febrero de 1939, tomo 3.
} 
fue suficiente para igualar resultados debido al acervo histórico de desigualdades ya existentes, el cual generaba que algunos sectores sociales obtuvieran mejores resultados en la competencia. En el fútbol local, Talleres y Belgrano fueron las entidades que, sobre la base de capacidades, relaciones y posiciones de poder construidas previamente, disfrutaron de mejores condiciones para sacar provecho del mercado profesional y diferenciarse del resto de los competidores. Ambos tenían una trayectoria histórica deportivamente exitosa y contaban con futbolistas cotizados en el ambiente; disponían de un gran caudal de jugadores, asociados y aficionados; vendían una importante cantidad de entradas a partidos y eventos sociales; contaban con el aporte personal de algunos de sus dirigentes o allegados; tenían mayores facilidades para acceder a subsidios estatales con los cuales, por ejemplo, construir sendos estadios de gran capacidad y comodidad; y recibían mayor cobertura mediática por parte de la prensa periódica, gracias a la que podían brindar mayor información, publicitar más masivamente sus eventos y lograr una mayor ascendencia y prestigio público, que era fuente de nuevas desigualdades al ejercer como poder de atracción de jugadores y aficionados. A lo largo de toda la década, estos clubes dispusieron de mayor capital económico para seguir comprando jugadores de los menos favorecidos como una forma de reforzar sus planteles y debilitar el potencial deportivo de sus rivales. Este tipo de estrategias influía en el proceso de conformación de grupos con potenciales diferenciados en la práctica deportiva y profundizaba las asimetrías existentes entre las mismas entidades profesionales.

En el plano deportivo del espectáculo rentado, estas dos instituciones acrecentaron su rivalidad y monopolizaron los éxitos durante su primera década de implementación y se repartieron los títulos más importantes hasta 1942, cuando el vencedor fue Universitario. Sus buenos resultados atraían mayores convocatorias y asociados, con cuyos ingresos podían nivelar los egresos propios de su actividad.

Sobre la base de esas condiciones, estos clubes tuvieron la capacidad económica y deportiva para generar otro tipo de estrategias competitivas en aras de expandir la oferta de espectáculos, diversificar sus fuentes de ingresos y capitalizar su posición ascendente en el mercado deportivo local y nacional. Se trataba de la posibilidad de gestionar giras de equipos foráneos a la ciudad. Con la firma de los convenios con las ligas profesionales, los equipos porteños volvieron a visitar Córdoba después de largo tiempo, lo que representaba uno de los eventos de mayor envergadura y convocatoria que podían darse en la ciudad. River Plate y Platense fueron los primeros en allegarse y sus presencias atrajeron gran cantidad de público. El concurso de los prestigiosos conjuntos metropolitanos se volvió un factor de competencia entre los clubes cordobeses, incluso al punto de gestionar la presencia de diferentes equipos en fechas coincidentes ${ }^{39}$. Para los visitantes, a su vez, parte del interés radicaba en la oportunidad de aumentar su prestigio a nivel nacional y observar jugadores de otro medio para poder contratarlos. A través de la ampliación del mercado competitivo con este tipo de eventos, los clubes buscaron

\footnotetext{
${ }^{39}$ Otras veces, cuando eran clubes grandes como Talleres y Belgrano los que organizaban partidos interprovinciales, resolvían suspender la jornada oficial del fin de semana, dejando sin la posibilidad de percibir ingresos por entradas en sus encuentros a las escuadras más chicas.
} 
Reyna. La desigualdad en las estructuras competitivas del fútbol profesional de Córdoba (Argentina) en la década...

producir un bien cultural que potenciara el consumo deportivo entre la población y concentrara sus beneficios entre unos pocos.

El poderío de estas instituciones y su capacidad para diversificar sus fuentes de capitalización también se reflejó económicamente. Por ejemplo, en las memorias del ejercicio del año 1938, el superávit de Talleres fue de $\$ 5.958,63$ y el Belgrano de $\$ 9.861,49^{40}$. Para 1942, las utilidades de este último club alcanzaron los $\$ 4.476,21^{41}$. También la LCF, que obtenía dividendos de las mejoras competitivas, desde 1938 comenzó a evidenciar una recuperación financiera por primera vez desde la profesionalización del fútbol, según se desprende de la Tabla 2:

Tabla 2. Balances económicos de la LCF

\begin{tabular}{lll}
\hline Año & Utilidades & Ingresos por recaudaciones \\
\hline 1937 & $\$-1.666,50$ & $\$ 5.809,22$ \\
\hline 1938 & $\$ 1.307,09$ & $\$ 5.981,25$ \\
\hline 1939 & $\$ 1.883,46$ & $\$ 7.635,94$ \\
\hline 1940 & $\$ 1.514,32$ & $\$ 7.659,82$ \\
\hline 1941 & $\$ 3.104,74$ & $\$ 9.883,29$ \\
\hline 1942 & $\$ 3.133,45$ & $\$ 12.168,84$ \\
\hline 1943 & $\$ 11.851,44$ & $\$ 23.549,64$ \\
\hline
\end{tabular}

Fuente: Elaboración propia sobre la base de datos suministrados por la Liga Cordobesa de Football. “Actas de Asamblea". 10 de febrero de 1939; 14 de febrero de 1940; 14 de febrero de 1941; 13 de febrero de $1942 ; 15$ de febrero de $1943 ; 15$ de febrero de 1944 . Tomo 3.

Mientras tanto, los demás clubes padecían una realidad más bien precaria y arrojaban balances con pérdidas: su cantidad de socios era exigua y algunas de sus recaudaciones no alcanzaban a reunir lo suficiente para afrontar los gastos de participación en los torneos oficiales. A modo de ejemplo, en un fin de semana del año 1938 en que se enfrentaban Talleres y Belgrano, estos recaudaron \$3.669,69, mientras que los tres partidos restantes (Lavalle vs. Instituto, Audax vs. Peñarol y Juniors vs. San Lorenzo) no llegaron en su conjunto a los $\$ 300^{42}$.

La prensa atribuía el limitado poder de convocatoria que tenía el resto de las entidades a dos razones principales, que evidenciaban claras asimetrías entre las instituciones deportivas locales. Por un lado, el problema radicaba en la pobreza de los espectáculos futbolísticos ofrecidos al público ante la falta de competitividad de sus planteles de jugadores. Por otro lado, la reglamentación por la que los equipos profesionales debían ejercer la localía en los estadios de la LCF y de Talleres y Belgrano -porque eran los únicos que cumplían con la disposición del ente regulador de tener

\footnotetext{
40 "Belgrano y Talleres tuvieron un superávit en su último ejercicio". (24 de enero de 1939). Los Principios, p. 9.

41 "Síntesis del balance del Club A. Belgrano". (12 de enero de 1943). Los Principios, p. 6.

42 "Lo que se recaudó en los partidos del Campeonato "Preparación”. (2 de junio de 1938). Los Principios, p. 9.
} 
600 metros de tribuna para ser habilitados $-{ }^{43}$ perjudicaba la concurrencia de público del resto de las instituciones con arraigo en las barriadas urbanas, ya que debían jugar lejos de su jurisdicción ${ }^{44}$. Así, las relaciones de fuerza desiguales en el mercado terminaban imponiendo también el radio de acción territorial de las entidades en competencia, lo cual además influía en sus posibilidades deportivas. Recién en 1942 la LCF se quedó sin cancha propia, eliminó las restricciones sobre los campos de juego y restituyó la localía al resto de las entidades, lo que propició un aumento significativo de las recaudaciones ${ }^{45}$. Además de descentralizar la geografía de los escenarios deportivos y atraer a nuevos aficionados, se potenciaban así las posibilidades deportivas de las demás instituciones, lo que fue revalidado con la consagración de un nuevo campeón, Universitario.

Las desigualdades se profundizaban en los clubes de segunda, ya que amén de tener escasa cantidad de socios y exiguos ingresos por venta de entradas, igualmente debían afrontar varias erogaciones como el alquiler de casillas para sus precarios campos de juego o los pagos a la LCF en concepto de porcentajes de recaudaciones, inscripciones, honorarios de referees y derechos de pases de jugadores, entre muchos otros. Constantemente reclamaban al ente federativo por la supresión o rebaja de estas cargas y proponían nuevas alternativas de competencia a fin de asegurar otras fuentes de ingresos para sus arcas, como la realización de un partido anual entre el ganador del torneo profesional y un combinado de las segundas ${ }^{46}$. En casos extremos, los recurrentes apremios económicos que sufrían estas instituciones llevaron a que se vieran obligadas a renunciar a su participación en la Liga, como Sportivo Barracas en $1943^{47}$.

De esta manera, la endeble prosperidad que el espectáculo profesional comenzaba a avizorar desde finales de la década del treinta se estructuraba a partir de la desigual distribución de recursos entre sus actores. Recién en los años peronistas varios de los clubes más chicos, que sobrevivían principalmente gracias a su anclaje en la comunidad barrial más próxima, el aporte de sus dirigentes y las ventas de sus jugadores, contaron con mayores ayudas y recursos para mejorar su crítica situación, aunque sin revertir el desequilibrio deportivo y económico ya acumulado.

\section{Conclusión}

Con la especialización y profesionalización del fútbol se institucionalizaron nuevas formas de desigualdad entre los diversos actores del universo deportivo a fines de potenciar el desarrollo y consumo masivo de los productos culturales que circulaban en el mercado de espectáculos locales. Además de las inequidades que se desarrollaron en la comercialización de los pases de jugadores, se destacaron las que tuvieron

\footnotetext{
43 "El fútbol debe ir a los barrios". (21 de enero de 1940). Los Principios, p. 8.

44 "El fútbol rentado no trajo a las entidades beneficio que les permitiera consolidarse". (1 de enero de 1938). La Voz del Interior, p. 20.

${ }^{45}$ Liga Cordobesa de Football. "Actas de Asamblea”. 15 de febrero de 1943, tomo 3, f. 120.

46 "Los clubs de fútbol de segunda pedirán hoy rebaja de aranceles". (9 de septiembre de 1942). Los Principios, p. 7.

47 "Temas deportivos. Ayuda a entidades pobres". (12 de marzo de 1943). Los Principios, p. 7.
} 
Reyna. La desigualdad en las estructuras competitivas del fútbol profesional de Córdoba (Argentina) en la década...

lugar en la estructuración de las competencias deportivas, las cuales acrecentaron los desequilibrios ya históricamente acumulados entre los clubes locales.

Sobre la base de recursos, capacidades relacionales, capitales simbólicos y vínculos de poder erigidos previamente, los clubes locales procuraron construir estructuras competitivas más eficientes para el espectáculo profesional. En los diferentes intercambios e interacciones que entablaron entre ellos, algunos pocos actuaron corporativamente y definieron mecanismos institucionales para poder monopolizar el acceso a los bienes en juego y excluir a otros de su reparto, a la vez que recrearon representaciones que legitimaron la estratificación resultante. Esta apropiación diferencial de recursos dotó de nuevos contenidos a las rivalidades entre los clubes de acuerdo a la jerarquización o degradación deportiva e institucional de sus posiciones.

De ese modo, gestaron nuevas reglamentaciones y procedimientos para intervenir en la distribución de los bienes producidos a partir del nuevo marco rentado, generando nuevas disparidades que resquebrajaban la igualdad de oportunidades en la que en teoría partían todos los clubes en las competencias deportivas. Esto generó innumerables controversias y conflictos por la arbitrariedad e injusticia de tales decisiones y delimitó un universo recreativo fragmentado por grupos desiguales. Así, mientras que en el espectáculo deportivo se naturalizaban las capacidades diferenciales que tenían los clubes para apropiarse de los recursos en juego, lo que mayormente se cuestionaba era la asimetría en las formas de distribuirlos durante la competencia, aunque eso no alcanzara para explicar la disparidad de los resultados del profesionalismo.

En efecto, los clubes que lograron los mejores resultados deportivos y económicos en estos años fueron los que, además de ser beneficiados por las modificaciones e innovaciones en los espacios de competencia, contaron también con recursos materiales y simbólicos suficientes acumulados previamente y conservaron la representatividad política necesaria en los órganos de decisión para poder así concentrar oportunidades en el mercado y favorecer sus intereses.

El desarrollo del espectáculo profesional en Córdoba fue en parte posible, entonces, gracias a procesos de acaparamiento de recursos y desigualdad en su distribución. En otras palabras, la disparidad en la apropiación de esos bienes fue fundamental para que aquellos que pudieran concentrarlos produjeran entretenimientos de calidad consumidos masivamente, dentro de las dimensiones del mercado deportivo local. El criterio de la rentabilidad se impuso en el fútbol con el fin de potenciar su consumo y maximizar sus beneficios para unos pocos, aumentando los niveles de inequidad. De esta forma, la desigualdad se conformó como un factor estructurado y estructurante del proceso de mayor mercantilización de la sociedad del espectáculo, del que también participaron otras expresiones culturales que estaban transformando la vida social de la época como el teatro, el tango y la naciente industrial cinematográfica. 


\section{Referencias Bibliográficas}

Alabarces, P. (2000). Fútbol y Patria. El fútbol y las narrativas de la Nación en la Argentina. Buenos Aires, Argentina: Prometeo.

Archivo Histórico de la Municipalidad de Córdoba. (1933-1934). Documentos del Concejo Deliberante. Liga Cordobesa de Football.

Archivo Histórico de la Municipalidad de Córdoba. (1933-1935). Actas de Sesiones del Concejo Deliberante. Liga Cordobesa de Football.

Asociación del Football Argentino. (1934-1935). Memoria y Balance General.

Asociación del Football Argentino. (1940). Estatuto y Reglamento General.

Bahamonde Magro, A. (2011). La escalada del deporte en España en los orígenes de la sociedad de masas, 1900-1936. En: X. Pujadas (Ed.), Atletas y ciudadanos. Historia social del deporte en España. 1870-2010. Madrid, España: Alianza Editorial, pp. 89-124.

Diario La Voz del Interior. (1934-1938).

Diario Los Principios. (1934-1943).

Freire Rodrígues, F. (2005). "Profesionalización y modernización en el fútbol brasileño". En: Entrepasados, 27, 53-72.

Frydenberg J. \& Sazbon, D. (2015). "La huelga de los jugadores en 1948”. En: R. Rein (comp.), La Cancha peronista: Fútbol y política, 1946- 1955. San Martín, Argentina: Universidad Nacional de Gral. San Martín. UNSAM EDITA, pp. 65-80. Frydenberg, J. (2005). "La profesionalización del fútbol argentino: entre una huelga de jugadores y la reestructuración del espectáculo". En: Entrepasados, 27, pp. 73-94.

Frydenberg, J. (2011). Historia Social del fútbol. Desde el amateurismo al profesionalismo. Buenos Aires, Argentina: Sudamericana.

Jarvie, G. (2011). "Social Division and Social Inequality". En: Sport Science Review, 20 (1-2), 95-109.

Kessler, G. (2014). Controversias sobre la desigualdad. Argentina, 2003-2013. Buenos Aires, Argentina: Fondo de Cultura Económica.

Liga Cordobesa de Football. (1910). Actas de Asamblea, tomo 2.

Liga Cordobesa de Football. (1910). Reglamentos. Córdoba: La Industrial.

Liga Cordobesa de Football. (1916). Estatuto y Reglamento General. Córdoba: Los Principios. Liga Cordobesa de Football. (1934). Actas de Asamblea, tomo 2.

Liga Cordobesa de Football. (1934-1939). Campeonatos.

Liga Cordobesa de Football. (1935). Actas de Asamblea, tomo 2.

Liga Cordobesa de Football. (1939). Actas de Asamblea, tomo 3.

Liga Cordobesa de Football. (1943). Actas de Asamblea, tomo 3.

Otero Carvajal, L. (2003). "Ocio y Deporte en el nacimiento de la sociedad de masas". En: Cuadernos de Historia Contemporánea, 25, 169-198.

Pérez Sáinz, J. P. (2016). Una historia de la desigualdad en América Latina. La barbarie de los mercados, desde el siglo XIX hasta hoy. Buenos Aires, Argentina: Siglo XXI.

Pujadas, X. \& Santacana, C. (2001). "La mercantilización del ocio deportivo en España.

El caso del fútbol, 1900-1928”. En: Historia Social, 41, 147-167. 
Reyna. La desigualdad en las estructuras competitivas del fútbol profesional de Córdoba (Argentina) en la década...

Reygadas, L. (2004). "Las redes de la desigualdad: un enfoque multidimensional”. En: Política y Cultura, 22, 7-25.

Reygadas, L. (2008). La apropiación. Destejiendo las redes de la desigualdad. Barcelona, España: Antrophos.

Reyna, F. (2015a). La difusión y apropiación del fútbol en el proceso de modernización en Córdoba (1900-1943). Actores, prácticas, representaciones e identidades sociales. Tesis inédita de PhD en Historia. Córdoba, Argentina: Universidad Nacional de Córdoba.

Reyna, F. (2015b). "La emergencia del profesionalismo en el fútbol de Córdoba (Argentina)". RECORDE: Revista de História do Esporte, 8 (1), 1-23.

Reyna, F. (2017). "La configuración de un mercado laboral deportivo en la profesionalización del fútbol. Córdoba (Argentina), 1930-1940". En: História Unisinos, 21 (1), 136-148.

Reyna, F. D. (2018). "El proceso de transformación de los clubes de fútbol en entidades sociales y deportivas en Córdoba (Argentina) en los años de entreguerras". En: Revista Trashumante, 11, 52-72.

Rohrer, T. \& Haller, M. (2015). "Sport und soziale Ungleichheit - Neue Befunde aus dem internationalen Vergleich". En: Köln Z Soziol, 67, 57-82.

Roldán, D. (2012). La invención de las masas: Ciudad, corporalidades y culturas. Rosario, 1910-1945. La Plata, Argentina: Universidad Nacional de La Plata.

Sanjurjo, J. (2011). "La mercantilización del fútbol español en los años veinte: de la implantación del profesionalismo al nacimiento del campeonato nacional de liga". En: Esporte e Sociedade, 18, 1-30.

Therborn, G. (2015). La desigualdad mata. Madrid, España: Alianza Editorial.

Tilly, C. (2015). La desigualdad persistente. Buenos Aires, Argentina: Manantial. 